\title{
Kinetics of quality changes in papayas (Carica papaya L.) coated with Malaysian stingless bee honey
}

\begin{abstract}
There have been increased efforts to identify new edible coating and preservative compounds derived from natural sources. This study aimed to investigate the effect of two different concentrations $(1.0 \%$ and $1.5 \%)$ of Malaysian stingless bee honey $(\mathrm{SBH})$ as an edible coating agent on the quality attributes of papayas (Carica papaya L.) during storage. Quality parameters such as fresh weight loss (FWL), firmness, soluble solids content (SSC), titratable acidity (TA), colour, and respiration rate were investigated during $12 \mathrm{~d}$ of storage at $12 \pm 1{ }^{\circ} \mathrm{C}$. The results indicated that papayas coated with $1.0 \%$ and $1.5 \%$ of SBH significantly retained their firmness, colour, SSC, and TA, in addition to the reduced FWL and respiration rate as well as delayed decay development in fruits compared to the uncoated samples. The results of the Field Emission Electron Microscopy revealed that the SBH coating also prevented the ultrastructural features of the mitochondria. In addition, the zero-order and first-order kinetic models fitted well with the experimental data for both coated and uncoated papayas using the Arrhenius law approach. These results suggest that the SBH-coated layer not only improved the postharvest quality of papayas during storage but also prolonged their storage life.
\end{abstract}

Keyword: Stingless bee honey; Papaya; Physicochemical quality; Kinetic changes; Mitochondria 